\title{
Yaşlı Bireylerin Cerrahi Girişim Sonrası Evde Yaşadıkları Sorunların Belirlenmesi
}

\author{
Ahmet Dinçer ${ }^{1} \oplus$, Şerife Kurşun² ${ }^{\circledR}$
}

'Osmangazi Üniversitesi, Sağlık Bilimleri Fakültesi, Hemşirelik Bölümü, Eskişehir, Türkiye ²Selçuk Üniversitesi, Sağlık Bilimleri Fakültesi, Hemşirelik Bölümü, Konya, Türkiye

Ahmet Dinçer, Arş. Gör. Şerife Kurşun, Dr. Öğr. Üyesi

*Bu makale 2-5 Kasım 2017'de Antalya'da gerçekleşen 2.Uluslararası ve 10. Ulusal Türk Cerrahi ve Ameliyathane Hemşireliği Kongresi'nde poster bildiri olarak sunulmuştur.

Illetişim:

Arş. Gör. Ahmet Dinçer

Osmangazi Üniversitesi, Sağlık Bilimleri

Fakültesi, Hemşirelik Bölümü, Eskişehir, Türkiye

Tel: +905434242095

E-Posta: dincerahmet42@gmail.com
ÖZET

Amaç: Araştırma, 65 yaş ve üstü bireylerin cerrahi girişim sonrası evde yaşadıkları sorunları belirlemek, sorun yaşama durumu ile sosyo-demografik özellikler arasındaki ilişkiyi değerlendirmek amacıyla tanımlayıcı olarak yapııldı.

Gereç ve Yöntem: Araştırma, Mart-Temmuz 2016 tarihleri arasında Konya il merkezinde bulunan bir tıp fakültesi hastanesinin cerrahi kliniklerinde gerçekleştirildi. Araştırmanın örneklemini bu cerrahi kliniklerde yatan ve cerrahi girişim geçiren 65 yaş ve üstü 227 birey oluşturdu. Veriler, bireylerin sosyo-demografik özelliklerini içeren tanıtıı bilgi formu ile taburculuk sonrası evde yaşanan sorunları belirlemeye yönelik soru formu kullanılarak birinci görüşsmede hasta odasında yüz yüze, ikinci görüşmede taburculuktan bir hafta sonra poliklinikte yüz yüze, poliklinikte görülmeyen hastalarla telefonla görüşülerek toplandı. Verilerin analizinde ortalama, standart sapma, medyan, sıklık ve oran, Mann Whitney U testi ve Pearson Ki-Kare testi (Yates Continuity Correction, Fisher's Exact test ve Fisher Freeman Halton) kullanıldı.

Bulgular: Araştırmada yaşlı bireylerin \%74,4'ünün taburculuk sonrası evde sorun yaşadığı belirlendi. Cerrahi girişim sonrası evde yaşanan sorunların türleri incelendiğinde en fazla cerrahi girişim bölgesi $(\% 64,3)$ ve öz-bakım aktivitesi'ne $(\% 52,9)$ ilişkin olduğu saptandı. Cinsiyet, bakımdan sorumlu olan kişinin kim olduğu, cerrahi girişim sonrası hastanede yatma süresi ve toplam hastanede yatma süresi ile evde sorun yaşama durumu arasında ilişki olduğu saptandı $(p<0,01)$.

Sonuç: Yaşlı bireylerin cerrahi girişim sonrası evde en fazla cerrahi girişim bölgesine ve özbakıma ilişkin sorunlar yaşadığı belirlenmiştir. Bu doğrultuda hemşirelik uygulamalarında yaşı bireylerin gereksinimleri ve özellikleri doğrultusunda bireyselleştirilmiş eğitimlerin yapılması ve cerrahi girişim sonrası evde yaşanan sorunların belirlenmesi ve kontrol altına alınmasında izlemlerin yapılması gerekmektedir.

Anahtar sözcükler: Cerrahi girişim, evde bakım, yaşılıık

\section{DETERMINING THE PROBLEMS EXPERIENCED BY THE ELDERLY AT HOME AFTER (FOLLOWING) SURGICAL INTERVENTIONS}

\section{ABSTRACT}

Objective: The study was conducted as a descriptive study to determine the problems experienced by individuals aged 65 years and older at home after surgical interventions and to evaluate the relationship between socio-demographic characteristics and problematic status.

Materials and Methods: The research was carried out between March and July 2016 in the surgical clinics of a university hospital in the city of Konya. The sample of the study consisted of 227 individuals aged 65 years and older who underwent surgical interventions in these surgical clinics. A questionnaire developed by the researcher was used for collecting the data. In the first meeting, the data were collected by the researcher face to face in patients' rooms and in the second meeting, they were collected face to face in the polyclinics a week after the discharge and the data of the patients who were not seen were collected over the phone. In the analysis of the data, mean, standard deviation, median, frequency and ratio, Mann Whitney $\mathrm{U}$ test and Pearson Chi-square test (Yates Continuity Correction, Fisher's Exact test and Fisher Freeman Halton) were used.

Findings: It was determined that $74,4 \%$ of the elderly individuals had problems at home after discharge. When these types of problems experienced at home after surgery were examined, it was found that most of them were related to the surgery area (64.3\%) followed by self-care activity (52.9\%). Statistically significant differences were found in relation to the gender who is responsible for the domiciliary care, previous periods while the patient stayed at the hospital , the surgery hospital where the patient stayed, the status of staying at the hospital after the surgery , length of and the total hospital stays in addition to the situation of living problems at home $(p<0,01)$.

Conclusions: It was determined that elderly individuals had problems mostly related to surgical interventions and self-care at home after surgical interventions. In this direction, it is necessary to make individualized training in accordance with the needs and characteristics of the elderly individuals in nursing practice and to follow and control the problems experienced at home after the surgical intervention.

Keywords: Surgical intervention, home care, elderly 
nsan yaşamının en hassas ve kaçınılmaz dönemi olan yaşııık; bireyin fonksiyonlarında ve davranışlarında önemli değişikliklerin yaşandığı, bazı aktiviteleri yapmakta ve yeni durumlara alışmakta zorlandığı, çevresel faktörlere uyum sağlama yeteneğinin azaldığı bir dönemdir (1). Dünya Sağlık Örgütü (DSÖ), 2016 yılında 65 yaş ve üstü bireylerin \%8,7'ye ulaştığını, 2050 yılında ise bu oranın \%22 olmasının beklendiğini açıklamıştır (2). Türkiye'de ise Türkiye İstatistik Kurumu (TUiK)'nun sunmuş olduğu "istatistiklerle Yaşlılar 2016" raporunda 65 yaş ve üstü nüfusun 2016 yılında \%8,3'e yükseldiğini ve 2023 yılında ise bu oranın \%10,2'ye yükselmesinin beklendiği bildirilmiştir (3). Organizmadaki pek çok sistemi etkileyen yaşlanma süreci ile birlikte bireylerde bilişsel ve duyusal fonksiyonlarda gerileme/kayıplar, çevresel faktörlere uyum sağlama yeteneğinde azalma gibi anatomik ve fizyolojik bir takım değişiklikler, vücut direncinde azalma ve kronik hastalıklarda artış meydana gelmektedir $(4,5)$. Yaşlı bireylerin çoğunu etkileyen kronik hastalıklar, hastane yatışlarına neden olmaktadır (6). Yaşlı bireylerde görülen kronik hastalıklar ve diğer sorunlar, yemek yeme, tuvalete gitme ve giyinme gibi günlük yaşam aktivitelerini (GYA) yerine getirmede sorunlara neden olmakta ve GYA'nden en az birinde zorlanan yaşlı bireylerde, fiziksel yetersizlikler meydana gelebilmektedir. GYA'nden bir ya da bir kaçını yerine getiremeyen yaşlılar bu fiziksel yetersizlik nedeni ile uzun süreli sağlık bakımına intiyaç duymaktadırlar (7).

Yaşlı nüfus sayısının artması ve teknolojik gelişmeler, yaşı bireylere uygulanan cerrahi girişim sayısını da artırmıştır. Yaşanan tüm bu gelişmeler yaşlı hastalara uygulanan cerrahi girişimlerin sonuçlarını önemli oranda düzeltmiş olsa da halen yüksek morbidite ve mortalite riski taşımaktadır. Yaşın ilerlemesi, cerrahi girişim için tek başına bir risk faktörü olmamakla birlikte var olan diğer hastalıklarla beraber fiziksel fonksiyonları olumsuz etkileyebilmekte ve özellikle büyük cerrahi girişimlerden sonra komplikasyon gelişme riskini artırabilmektedir $(8,9)$. Ayrıca bu yaş grubu, cerrahi girişimin neden olduğu stresle baş etmede de güçlük yaşamaktadırlar (10). Genç bireylerle kıyaslandığında yaşı bireylerde cerrahi girişim sonrası komplikasyon görülme oranının daha yüksek olduğu belirtilmektedir (11). Yaşlı bireylerde cerrahi girişim sonrası dönemde sık karşılaşılan komplikasyonlar hipotansiyon, solunum yetersizliği, enfeksiyonlar ve deliryumdur $(12,13)$. Bunların yanı sıra konstipasyon, uyku düzeninde ve konforda bozulma (14) ve hipotermi (15) de cerrahi girişim sonrası görülen diğer sorunlardır. Bu komplikasyonlar; iyileşmenin gecikmesine, yoğun bakım ünitesi ve hastanede yatış süresinin uzamasına ve maliyetin artmasına neden olmaktadır (14).
Cerrahi girişim sonrası hastalar evde ağrı, kanama, uyku sorunları, yara yeri açılması ve sızıntı, yara enfeksiyonu, solunum güçlüğü, ödem, hareket kısıtlılığı, tek başına banyo yapamama, tek başına tuvalete gidememe, iştahsızlık, konstipasyon ve diyare gibi sorunlar yaşamaktadırlar $(16,17,18)$. Ayrıca, hastalarda evde bulantı ve kusma, baş dönmesi, boğaz ağrısı gibi sorunlar görülebilmekte ve bunlar hasta konforunu azaltabilmekte ve yaşamı tehdit edebilmektedir (19). Bununla birlikte hastaların evde karşılaştığı ağrı, bulantı ve kusma gibi sorunlar yeniden hastaneye yatışlara neden olmaktadır $(19,20)$. Genel olarak cerrahi girişim öncesi ve sonrasında yaşlı hastaların bakımındaki amaç hastanın sağlığının en üst düzeyde sağlanması ve komplikasyonların önlenmesidir. Cerrahi girişim sonrası sonuçların olumlu yönde etkilenmesi cerrahi girişim öncesinde yaşlı hasta için yapılacak iyi bir değerlendirme ile mümkün olmaktadır. Bu nedenle yaşlı bireylerin cerrahi girişim öncesinde yaşlılığın getirdiği değişiklikler ve yapılacak olan girişimin niteliği ve riskleri yönünden kapsamlı şekilde değerlendirilmesi gerekmektedir (21).

Taburculuktan sonra belirgin hale gelen sorunlar, hem hasta hem de ailesi için ciddi sorun oluşturmakta ve yardım gereksinimlerini artırmaktadır (22). İyi planlanmış taburculuk eğitimi ile hastanın hastanede kalış süresi, tekrarlı yatışlar ve sağlık bakım giderleri azaltılabilmekte; komplikasyonlar erken dönemde saptanabilmekte ve komplikasyonların gelişmesi önlenebilmektedir (23). Yapılan bir çalışmada taburculuk eğitimi ve danışmanlık hizmeti alan koroner arter bypass greft cerrahisi geçiren hastaların anksiyete ve depresyon düzeylerinin düşük olduğunu saptanmıştır (24).

Cerrahi girişim sonrası hasta bireyler kendi bakımlarını sürdürebilmek için ayrıntılı bilgiye gereksinim duyarlar. Mümkünse, taburculuk öncesi hasta kendi bakımını sürdürebilecek fiziksel ve psikolojik yeterliliğe getirilmeli, taburculuk sonrası evde bakıma ilişkin ayrıntılı olarak bilgilendirilmelidir (25). Hemşireler, taburculuk sonrası hastanın gereksinimi olan bakımı almasını sağlamak ve hasta bireyin olumsuz olarak etkilenmesini önlemek amacıyla hastanın bakımında etkin rol alacak aile üyelerine hasta bireye özgü bakımı öğretmelidir $(1,26)$. Taburculuğa hazırlanma ile birlikte cerrahi girişim geçiren yaşlı bireylerin evdeki yaşamlarında uyumlarının değerlendirilmesi, yaşadıkları sorunların saptanması önemlidir. Bu bağlamda araştırma, yaşlı bireylerin cerrahi girişim sonrası evde yaşadıkları sorunların ve bu sorunlarla ilişkili faktörlerin belirlenmesi amacıyla yapıldı. 


\section{Gereç ve yöntem}

Tanımlayıcı tipteki bu araştırma, 15 Mart-16 Temmuz 2016 tarihleri arasında Konya il merkezinde bulunan bir tıp fakültesi hastanesinde gerçekleştirildi. Araştırmanın evrenini, beyin cerrahi, genel cerrahi, göz hastalıkları, göğüs cerrahisi, jinekoloji, kalp ve damar cerrahisi, kulak burun boğaz cerrahisi, ortopedi ve travmatoloji, plastik ve rekonstrüktif cerrahi ve üroloji kliniklerinde cerrahi girişim geçiren 907 yaşlı birey oluşturdu. Araştırmada örnek sayısının belirlenmesinde, Dal ve ark (2012) tarafından yapılan çalışmada cerrahi girişim sonrası hastaların evde yaşadıkları sorunların görülme oranı $(\% 7,7-70,9)$ dikkate alınarak ortalama etki büyüklüğü 0,236 olarak hesaplandı. Etki büyüklüğü göz önünde bulundurularak alfa değeri 0,05 ve güç düzeyi 0,90 kabul edilerek bu çalışma için gerekli minimum örneklem büyüklüğü 227 olarak belirlendi. Hesaplamalar GPower 3.1 programında yapıldı. Örneklem seçiminde tabakalı örnekleme yöntemi kullanıldı. Selçuk Üniversitesi Sağlık Bilimleri Fakültesi Dekanlığı Girişimsel Olmayan Klinik Araştırmalar Etik Kurul izni (23.02.2016 tarihli 2016/19 karar sayılı) ve hastanenin Başhekimliğinden kurum izni alındı. Araştırmaya katılan hastalar ve aileleri ile görüşülerek araştırmanın amacı ve içeriği hakkında açıklama yapılarak araştırma katılmayı kabul ettiklerine dair sözel olurları alındı. Veriler, cerrahi girişim geçiren yaşlı bireyin sosyo-demografik ve sağlık özelliklerini içeren tanıtıcı bilgi formu ile taburculuk sonrası evde yaşanan sorunları belirlemeye yönelik soru formu kullanılarak toplandı. Araştırma verileri araştırmacı tarafından birinci görüşmede hasta odalarında yüz yüze, ikinci görüşmede taburculuktan bir hafta sonra poliklinikte yüz yüze, poliklinikte görülmeyen hastalarla telefonla görüşülerek toplanmıştır. Verilerin analizinde ortalama, standart sapma, medyan, sıklık ve oran, Mann Whitney U testi ve Pearson Ki-Kare testi (Yates Continuity Correction, Fisher's Exact test ve Fisher Freeman Halton) kullanılmıştır. Sonuçlar $\% 95$ 'lik güven aralığında, anlamlıık $p<0,05$ düzeyinde değerlendirildi.

\section{Bulgular}

Araştırma kapsamına alınan yaşı bireylerin \%69,6'sı 65-74 yaş grubunda ve $\% 77,5^{\prime} i$ erkek, \%64,8'i ilkokul mezunu, \%77,5'i evli ve tamamı (\%100) en az bir çocuk sahibidir. Yaşlı bireylerin çoğunluğunun $(\% 99,6)$ sosyal güvencesinin olduğu ve çoğunluğunun $(\% 94,3)$ çalışmadığı belirlenmiştir. Yaşlı bireylerin çoğunluğunun $(\% 94,7)$ aylık gelire sahip olduğu, \%63,4'ünün ilde yaşadığı, çoğunluğunun $(\% 86,3)$ bakımına yardımcı bireyin olduğu ve $\% 36,2$ 'sinin bakımından sorumlu kişinin oğlu olduğu belirlendi (Tablo 1).
Tablo 1. Yaşlı bireylere ilişkin demogrofik özellikler $(n=227)$

\begin{tabular}{|c|c|c|}
\hline Özellikler & Sayı & $\%$ \\
\hline \multicolumn{3}{|l|}{ Yaş } \\
\hline $65-74$ yaş & 158 & 69,6 \\
\hline $75-84$ yaş & 66 & 29,1 \\
\hline 85 yaş ve üstü & 3 & 1,3 \\
\hline \multicolumn{3}{|l|}{ Cinsiyet } \\
\hline Kadın & 51 & 22,5 \\
\hline Erkek & 176 & 77,5 \\
\hline \multicolumn{3}{|l|}{ Eğitim durumu } \\
\hline Okuryazar & 51 & 22,5 \\
\hline ilkokul & 147 & 64,8 \\
\hline Ortaokul & 23 & 10,1 \\
\hline Lise & 3 & 1,3 \\
\hline Üniversite & 3 & 1,3 \\
\hline \multicolumn{3}{|l|}{ Medeni durumu } \\
\hline Evli & 176 & 77,5 \\
\hline Boşanmış/dul & 51 & 22,5 \\
\hline \multicolumn{3}{|l|}{ Sosyal güvence varlığı } \\
\hline Var & 226 & 99,6 \\
\hline Yok & 1 & 0,4 \\
\hline \multicolumn{3}{|l|}{ Çalışma durumu } \\
\hline Çalışıyor & 13 & 5,7 \\
\hline Çalışmıyor & 214 & 94,3 \\
\hline \multicolumn{3}{|l|}{ Çocuk sayısı } \\
\hline Bir çocuk & 10 & 4,4 \\
\hline İki-üç çocuk & 131 & 57,7 \\
\hline Dört ve daha fazla çocuk & 86 & 37,9 \\
\hline \multicolumn{3}{|c|}{ Aylık gelire sahip olma durumu } \\
\hline Evet & 215 & 94,7 \\
\hline Hayır & 12 & 5,3 \\
\hline \multicolumn{3}{|l|}{ Bakımdan sorumlu kişi } \\
\hline Eşi & 55 & 28,1 \\
\hline $\mathrm{KIZI}$ & 48 & 24,5 \\
\hline Oğlu & 71 & 36,2 \\
\hline Torunu & 10 & 5,1 \\
\hline Diğer & 12 & 6,1 \\
\hline \multicolumn{3}{|c|}{ Bakıma yardımcı birey varlığı } \\
\hline Evet & 196 & 86,3 \\
\hline Hayır & 31 & 13,7 \\
\hline \multicolumn{3}{|l|}{ Yaşanılan yer } \\
\hline il & 144 & 63,4 \\
\hline İlçe & 62 & 27,3 \\
\hline Köy & 21 & 9,3 \\
\hline
\end{tabular}


Çalışma kapsamına alınan yaşlı bireylerin $\% 74,4^{\prime}$ ünün cerrahi girişim sonrası evde sorun yaşadığı, en fazla cerrahi girişim bölgesi $(\% 64,3)$ ve öz-bakım aktivitesi $(\% 52,9)$, en az ise ilaç kullanımı $(\% 5,7)$ ve gastrointestinal sisteme $(\% 10,1)$ yönelik sorunlar olduğu belirlendi. Hastaların $\% 67,8^{\prime}$ i verilen taburculuk eğitiminin evde yaşanan sorunların kontrolünde yararlı olduğunu belirtti (Tablo 2).

Tablo 2. Yaşı bireylerin cerrahi girişim sonrası evde sorun yaşama

durumu ve yaşanan sorun türlerinin dağılımı $(n=227)$

\begin{tabular}{lccccc} 
Özellikler & \multicolumn{2}{c}{ Evet } & \multicolumn{2}{c}{ Hayır } \\
\hline & Sayı & $\%$ & Sayı & $\%$ \\
\hline $\begin{array}{l}\text { Cerrahi girişim sonrası evde sorun yaşama } \\
\text { durumu }\end{array}$ & 169 & 74,4 & 58 & 25,6 \\
Cerrahi girişim sonrası evde yaşanan sorunlar & & & & \\
Solunum sistemine yönelik sorunlar & 58 & 25,6 & 169 & 74,4 \\
Dolaşım sistemine yönelik sorunlar & 87 & 38,3 & 140 & 61,7 \\
Boşaltım sistemine yönelik sorunlar & 68 & 30,0 & 159 & 70,0 \\
Gastrointestinal sisteme yönelik sorunlar & 23 & 10,1 & 204 & 89,9 \\
Hareket sistemine yönelik sorunlar & 82 & 36,1 & 145 & 63,9 \\
Illaç kullanımına yönelik sorunlar & 13 & 5,7 & 214 & 94,3 \\
Cerrahi girişim bölgesine yönelik sorunlar & 146 & 64,3 & 81 & 35,7 \\
Uyku aktivitesine yönelik sorunlar & 24 & 10,6 & 203 & 89,4 \\
Öz bakım aktivitesine yönelik sorunlar & 120 & 52,9 & 107 & 47,1 \\
Diğer sorunlar* & 35 & 15,4 & 192 & 84,6 \\
Verilen taburculuk eğitiminin yaşanan sorunlara & 154 & 67,8 & 15 & 15,4 \\
yönelik yarar sağlama durumu (n=169) & & & &
\end{tabular}

* Düşme, gastroözofagal reflü ve burun kanaması.

Cerrahi girişim sonrası evde sorun yaşama durumu ile yaş, eğitim durumu, medeni durum, sosyal güvence varlığı, çalışma durumu, aylık gelire sahip olma durumu ve çocuk sayısı ve bakıma yardımcı birey varlığı arasında istatistiksel olarak anlamlı bir fark olmadığı saptandı $(p>0,05)$. Bununla birlikte cinsiyet ve bakıma yardımcı kişinin kim olduğu ile cerrahi girişim sonrası evde sorun yaşama arasında ilişki olduğu, kadın hastalarda ve kızı, oğlu ya da torunu tarafından bakılan hastalarda cerrahi girişim sonrası evde sorun yaşama oranının anlamlı düzeyde yüksek olduğu saptandı $(p<0,01)$ (Tablo 3).

Çalışma kapsamına alınan yaşlı bireyler cerrahi girişim sonrası ortalama 3,87 $\pm 3,44$ gün (Min=1, Maks=30), toplamda ise 4,7 \pm 3 ,88 gün (Min=1, Maks=32) hastanede yatmıştır. Cerrahi girişim sonrası hastanede yatılan gün sayısı ve hastanede toplam yatılan gün sayısı uzun olan yaşlı bireylerin evde sorun yaşama oranlarının diğer gruba göre daha yüksek olduğu belirlendi ( $p<0,01$ ) (Tablo 4).

Tablo 3. Yaşlı bireylerin sosyo-demografik özellikleri ile cerrahi girişim sonrası evde sorun yaşama durumu arasındaki ilişki.

\begin{tabular}{llllllll} 
Özellikler & \multicolumn{1}{l}{ Evet } & \multicolumn{3}{l}{ Hayır } \\
\hline & $n$ & $\%$ & $n$ & $\%$ & $x^{2}$ & $p$
\end{tabular}

Yaş

65-74 yaş

75-84 yaş

85 ve üstü yaş

Cinsiyet

Kadın

Erkek

Eğitim durumu

Düşük

Orta düzey

IIleri düzey

Medeni durumu

Evli

Boşanmış/dul

Sosyal güvence

Var

Yok

Çalışma durumu

Çalışıyor

Çalışmıyor

$\begin{array}{llll}11 & 84,6 & 2 & 15,4\end{array}$

$158 \quad 73,8 \quad 56 \quad 26,2$

$0,749 \quad 20,524$

Aylık gelire sahip olma durumu

Evet

Hayır

\section{Çocuk sayısı}

Bir çocuk

iki-üç çocuk

Dört ve daha fazla

Yaşanılan yer

il

illçe

Köy

Bakıma yardımcı birey varlığı

Evet

Hayır

Bakıma yardımcı kişinin kim olduğu

$\begin{array}{lcccccc}\text { Eşi } & 34 & 61,8 & 21 & 38,2 & & \\ \text { Kızı } & 42 & 87,5 & 6 & 12,5 & & \\ \text { Oğlu } & 54 & 76,1 & 17 & 23,9 & 9,633 & \mathbf{3 0}^{\mathbf{0}, 040} \text { * } \\ \text { Torunu } & 8 & 80,0 & 2 & 20,0 & & \\ \text { Diğer (Bakıcı, komşu) } & 8 & 66,7 & 4 & 33,3 & & \end{array}$

${ }^{1}$ Yates Continuity Correction, ${ }^{2}$ Fisher's Exact test, ${ }^{3}$ Fisher Freeman Halton test

${ }^{\star} p<0,05,{ }^{* *} p<0,01$ 
Tablo 4. Yaşlı bireylerin hastanede yatma özellikleri ile cerrahi girişim sonrası evde sorun yaşama durumu arasındaki ilişki

\begin{tabular}{|c|c|c|c|c|c|c|}
\hline \multirow[b]{2}{*}{ Özellikler } & \multicolumn{2}{|c|}{ Evet } & \multicolumn{2}{|c|}{ Hayır } & \multirow[b]{2}{*}{$Z$} & \multirow[b]{2}{*}{$p$} \\
\hline & Ort $\pm S S$ & Min-maks. & Ort $\pm S S$ & Min-maks. & & \\
\hline $\begin{array}{l}\text { Cerrahi girişim sonrası hastanede } \\
\text { yatma süresi (gün) }\end{array}$ & $3,87 \pm 3,44$ & $1-30$ & $2,21 \pm 1,76$ & $1-11$ & $-5,536$ & ${ }^{4} 0,001^{* *}$ \\
\hline Toplam hastanede yatma süresi (gün) & $4,7 \pm 3,88$ & $1-32$ & $2,53 \pm 1,75$ & $1-11$ & $-6,617$ & ${ }^{4} 0,001$ ** \\
\hline
\end{tabular}

\section{Tartışma}

Cerrahi girişim sonrası dönemde iyi planlanmış bir taburculuk eğitimi, iyileşme sürecini hızlandırmakta ve komplikasyonların önlenmesini sağlamaktadır (27). Ülkemizdeki beklenen yaşam süresi ve yaşı nüfus sayısı dikkate alındığında, cerrahi girişimlerin orta ve ileri yaş gruplarında da sıklıkla uygulandığı görülmektedir.

Çalışmada yaşlı bireylerin $\% 74,4^{\prime}$ ü cerrahi girişim sonrası evde en az bir sorun yaşamaktadır (Tablo 2). Literatür taramasında (Pubmed, National Library of Medicine, Ebscohost, Ulakbim veri tabanları) yaşlı bireyle ile yapılan benzer çalışmalara rastlanılamamakla birlikte, farklı yaş grupları ve farklı cerrahi türleri ile yapılan bir çalışmada bireylerin cerrahi girişim sonrası evde en az bir sorun yaşama oranı $\% 88,3$ bulunmuştur (28). Bu sonuçlar cerrahi türlere göre farklılık göstermekle birlikte bireylerin cerrahi girişim sonrası evlerinde sorun yaşadıklarını göstermektedir. Bu bağlamda cerrahi türleri dikkate alınarak taburculuk eğitiminde evde yaşanabilecek sorunlara ve çözüme yer verilmelidir. Çalışmada bireylerin en fazla cerrahi girişim bölgesi ve öz-bakım aktivitesine, en az ise ilaç kullanımı ve gastrointestinal sisteme yönelik sorun yaşadıkları saptandı (Tablo 2). Yapılan çalışmalar incelendiğinde cerrahi girişim sonrası hastaların en fazla yaşadıkları sorunlar içinde ağrı $(\% 70,9)$, öz bakım aktivitesi $(\% 40,8)(18)$, cerrahi girişim bölgesi $(\% 78,1)(29)$, en az ise ilaç kullanımına (\%21,9 ve $\% 7,7)$ yönelik olduğu belirlenmiştir $(18,29)$. Araştırma bulguları cerrahi girişim sonrası bireylerin çoğunlukla ağrı kontrolüne ve öz bakıma ilişkin sorunlar yaşadığını göstermektedir. Bu durum yaşlı bireylerin cerrahi girişim sonrası evde bakıma intiyaç duyduklarını düşündürmektedir.

$\mathrm{Bu}$ çalışmada, yaş ve eğitim durumu ile cerrahi girişim sonrası evde sorun yaşama durumu arasında fark olmadığı $(p>0,05)$ belirlenmekle birlikte ileri yaştaki hastaların ve eğitim durumu düşük olanların sorun yaşama oranı daha yüksektir (Tablo 3). Yapılan bir çalışmada da bu çalışma ile benzer şekilde yaş ve eğitim durumu (18) ile hastaların evde sorun yaşama durumu arasında fark olmadığı belirlenmiştir. Çalışmada cerrahi girişim sonrası kadınlarda evde sorun yaşama oranın erkeklerden daha yüksek olduğu saptandı $(p<0,01)$ (Tablo 3). Cerrahi girişim sonrası dönemde kadın hastaların erkeklere göre komplikasyon yaşamaya daha fazla yatkın olduklarını bildirmiştir (30). Yapılan diğer bir çaıışmada ise cerrahi girişim sonrası erkek hastaların kadınlara göre daha az sorun yaşadığı ve yaşam kalitelerinin daha yüksek olduğu belirlenmiştir (31). Kadınların erkeklere göre daha fazla sorun yaşamasının nedeninin, ülkemizde yaşlanma ile birlikte cerrahi girişim geçiren kadınların bakımının kendisi ya da diğer kişiler (çocuklar, akraba ya da bakıcı) tarafından, erkek hastaların bakımının ise özellikle eşi ya da diğer kişiler (çocuklar, akraba ya da bakıcı) tarafından sağlanmasına bağlı olduğu düşünülmektedir. Yaşlı bireylerin cerrahi girişim sonrası evde sorun yaşama oranlarının, yaşlı bireyin bakımından sorumlu yardımcı birey bulunma durumuna göre farklılık göstermediği $(p>0,05)$ ancak bakımdan sorumlu kişiye göre sorun yaşama oranında farklılık olduğu belirlenmiştir $(p<0,05)$. Evinde eşi ve diğer kişiler (bakıcı ve komşu) tarafından bakımına yardım edilen yaşlı bireylerin evde sorun yaşama oranının kızı, oğlu ve torunu tarafından bakılan yaşılıara göre düşük olduğu saptanmıştır (Tablo 3). Bu durum yaşlı bireyin evde yaşadığı sorunları azaltan faktörün aynı evi paylaşan kişiler (eşi veya bakıcısı) olduğunu düşündürmektedir.

Çalışmada cerrahi girişim öncesi ve sonrası hastanede daha uzun yatan bireylerin evde daha fazla sorun yaşadıkları belirlendi $(p<0,05)$ (Tablo 4). Bazı çalışmalarda uzun süre hastanede yatan bireylerin hastalıklar yönünden riskli oldukları belirlenmiştir $(32,33)$. Literatürde de belirtildiği gibi hastane yatışlarında erken taburculuğun bireyin hastalıklara yakalanma riskini azalttığı anlaşılmaktadır.

Araştırmadan elde edilen sonuçlar yaşlı bireylerin evde yaşadıkları sorunların önemini ortaya koymaktadır. Kliniklerde taburculuk eğitiminin planlı olarak yapılması ve hemşirelik uygulamalarının bir parçası haline getirilmesi, yaşlı bireylerin cerrahi girişim sonrası evde bakıma ilişkin ayrıntılı bilgilendirilmesi, bu bilgilendirme ve eğitim sürecinde hemşirelerin aktif rol oynaması, yaşlı bireylerin cerrahi girişim sonrası evde bakımına destek olacak bireylerin katılmasının sağlanması ve bilgilendirilmesi, yaşlı bireylerin cerrahi girişim sonrası evde ziyaret edilmesi, ayrıca çalışmanın spesifik cerrahi alanlarda yapılması önerilmektedir. 


\section{Kaynaklar}

1. Arpacı F. Farklı Boyutları İle Yaşlılık 1. Baskı. Ankara: Türkiye İşçi Emeklileri Derneği Kültür Yayınları; 2005; ss.15-40.

2. World Health Organization 2015. Ageing and health. Erişim: https:// www.who.int/en/news-room/fact-sheets/detail/ageing-and-health

3. Türkiye İstatistik Kurumu (TÜiK), 2014. İstatistiklerle Yaşlılar 2014 Bülteni. Erişim tarihi:22 Ekim 2016, Erişim adresi, http://www.tuik. gov.tr/PreHaberBultenleri.do?id=18620

4. Erdil F, Çelik SS, Baybuğa MS. Yaşıılık ve Hemşirelik Hizmetleri. İçinde: Kutsal YG, editör. Yaşlılık Gerçeği, 1. Baskı. Ankara: GEBAM; 2004. ss.57-78.

5. Altındiş M. Yaşlılarda Güncel Sağlık Sorunları ve Bakımı, 1. Baskı. İstanbul: Ekspress Basımevi; 2013. ss.22-5.

6. Heitkemper MM. Older Adults. In: Lewis MS, Meitkemper MM, Dirksen RS, editors. Medical Surgical Nursing Assesment and Manegement of Clinical Prolems,Vol 2. 6th ed. St. Louis, Missouri; Elsevier Saunders; 2004. pp.58-80.

7. Gönen E, Özmete E. Uzun süreli bakıma karar vermede bilgi teknolojisinden yararlanma 1. Ulusal Yaşlılık Kongresi Kitabı. Ankara: 2001; ss.318-31.

8. Blansfield JA, Clark SC, Hofmann MT, Morris JB. Alimentary Tract Surgery in the Nonagenarian: Elective vs. Emergent Operations. J Gast Surg 2004;8:539-42. [CrossRef]

9. Oruç TM, Uzun S, Saylam B, Karakahya M, Karadağ Ç, Düzgün Polat A, et al. Illeri Yaşta Acil ve Elektif Şartlarda Cerrahi Tedavi. Türk Geriatri Derg 2004;7:37-40.

10. Çelik S, Kavacık D, Nair A, Şeker N, Demirel L. Cerrahi Girişim Geçiren Yaşlı Hastalarda Bilişsel Fonksiyon Bozukluğunun Değerlendirilmesi. Bakırköy Tıp Derg 2015;11:66-73. [CrossRef]

11. Vatansev C, Tekin A. Hernia Repair in Elderly Patients. Turkiye Klinikleri J Surg Med Sci 2006;2:86-8.

12. Wallace J. Geriatrik Cerrahi. İçinde: Özmen MM, Başkan S, editörler. Cerrahide Karar Verme, 5. Baskı. Ankara: Güneş Tıp Kitabevi; 2007. ss.38-40.

13. Aygın D, Aslan FE, Cengiz H. Yaşlı Cerrahi Hastasında Ameliyat Sonrası Erken Dönem. Akademik Geriatri Derg 2011;4:12-7.

14. Chen X, Zhao M, White PF, Fanzca LS, Tang J, Wender RH, et al. The Recovery of Cognitive Function After General Anesthesia in Elderly Patients: a Comparison of Desflurane and Sevoflurane. Anesth Analg 2001;93:1489-94. [CrossRef]

15. Farella C. Handle with Care: Geriatric Patients Need Gentle Touch in Perioperative Practice. Nurs Spect (Florida Edition) 2001;11:8-9.

16. Çilingir D, Bayraktar N. Burun Ameliyatı Geçiren Hastaların Ameliyat Sonrası Illk Üç Gün İçinde Evde Yaşadıkları Sorunlar ve Bu Sorunların Çözümlenmesine Yönelik Uygulamaları. Türkiye Klinikleri J Nurs Sci 2009;1:71-80.

17. Uras C. Ameliyat sonrası komplikasyonlar, 2010. Erişim (5 Eylül 2010): http://www.ctf.edu.tr/anabilimdallari/pdf/
18. Dal Ü, Bulut H, Güler Demir S. Cerrahi Girişim Sonrası Hastaların Evde Yaşadıkları Sorunlar. Bakırköy Tıp Derg 2012;8:34-40. [CrossRef]

19. Mc Millan R. Day Surgery. In:Woodhead K, Wicker P, editors. Principles of Care in Different Environments. Edinburg: Cruchill Elsevier; 2005. p.99.

20. Jenkins D, Grady D, Wong J, Correa R, Armanious S, Chung F. Postoperative Recovery: Day Surgery Patients' Preferences. Br J Anaest 2001;86:272-74. [CrossRef]

21. Taşdemir N, Şenol Çelik S. Hastaların Cerrahi Girişim Sonrası Abdominal Distansiyona Yönelik Deneyimleri. Ege Üniv Hem YO Derg 2010;26:11-22.

22. Costa MJ. The Lived Perioperative Experience of Ambulatory Surgery Patients. AORN J 2001;74:874-81. [CrossRef]

23. Arıogul S. Geriatri ve Gerontoloji, 1. Baskı. Ankara: MN Medikal ve Nobel Tıp Kitabevi; 2006. ss.22-35.

24. Cebeci F, Şenol Çelik Ş. Effects of Discharge Teaching and Counselling on Anxiety and Depression Level of CABG Patients. Turk J Thor Card Surg 2011;19:170-6. [CrossRef]

25. Eti Aslan F. Ameliyat Sonrası Bakım. İçinde: Karadakovan A, Eti Aslan F, editörler. Dahili ve Cerrahi Hastalıklarda Bakım, 2. Baskı. Adana: Nobel Kitabevi; 2011. ss.338-9.

26. İnci FH, Erdem M. Bakım Verme Yükü Ölçeği'nin Türkçe'ye Uyarlanması, Geçerlilik ve Güvenirliği. Atatürk Üniv Hem YO Derg 2008;11:4.

27. Özcan H, Yıldız Fındık U, Süt N. Information Level of Patients in Discharge Training Given by Nurses Following Open Heart Surgery. Int J Nurs Pract 2010;16:289-94. [CrossRef]

28. Tok A, Şenol Çelik S. Koroner Anjiyoplasti ve İntrakoroner Stent Uygulanan Hastaların Taburculuk Sonrası Yasadıkları Sorunlar. Türkiye Klinikleri J Nurs 2009;1:47-55.

29. Aydın E. Bariatrik cerrahi uygulanan bireylerin ameliyat sonrası yaşadıkları güçlüklerin belirlenmesi. Yüksek Lisans Tezi, Gazi Üniversitesi Sağlık Bilimleri Enstitüsü, Ankara 2012.

30. Mattila K, Toivonen J, Janhunen L, Rosenberg H, Hynynen M. Post dischsrge syptoms after ambulatory surgery: first-week incidence, intensity, and risk factors. Anesth Analg 2005;101:1643-50. [CrossRef]

31. Chiu JH, Bhatt DL, Ziada KM, Chew DP, Whitlow PL, Lincoff AM, et al. Impact of Female Sex on Outcome After Percutaneous Coronary Intervention. Am Heart J 2004;148:998-1002. [CrossRef]

32. Ocaktan ME, Keklik A, Çöl M. Abidinpaşa Sağlık Grup Başkanlığı'na Bağlı Sağlık Ocaklarında Çalışan Sağlık Personelinde Spielberger Durumluluk ve Sürekli Kaygı Düzeyi. Ankara Üniv Tıp Fak Mecm 2002;55:21-8.

33. Çelik HC, Acar T. Kronik Hemodiyaliz Hastalarında Depresyon ve Anksiyete Düzeylerinin Çeşitli Değişkenlere Göre İncelenmesi. Fırat Tıp Derg 2007;12:23-7. Erişim: http://www.firattipdergisi.com/pdf/ pdf_FTD_363.pdf 